\title{
Tsafon
}

Revue d'études juives du Nord

$78 \mid 2019$

L'antijudaïsme dans l'Antiquité

\section{Tobias Norman C., La conscience juive de l'Église. Jules Isaac et le concile Vatican II}

\section{Olivier Rota}

\section{(2) OpenEdition \\ 1 Journals}

\section{Édition électronique}

URL : https://journals.openedition.org/tsafon/2625

DOI : $10.4000 /$ tsafon. 2625

ISSN : 2609-6420

\section{Éditeur}

Association Jean-Marie Delmaire

\section{Édition imprimée}

Date de publication : 1 décembre 2019

Pagination : 180-182

ISSN : 1149-6630

\section{Référence électronique}

Olivier Rota, «Tobias Norman C., La conscience juive de l'Église. Jules Isaac et le concile Vatican II », Tsafon [En ligne], 78| 2019, mis en ligne le 01 décembre 2019, consulté le 26 juin 2021. URL : http:// journals.openedition.org/tsafon/2625; DOI : https://doi.org/10.4000/tsafon.2625

Ce document a été généré automatiquement le 26 juin 2021.

Tsafon. Revues d'études juives du Nord 


\title{
Tobias Norman C., La conscience juive de l'Église. Jules Isaac et le concile Vatican II
}

\author{
Olivier Rota
}

\section{RÉFÉRENCE}

Paris, Salvator, 387 p., $22 €$

1 Jules Isaac a bénéficié en 2002 d'une étude biographique d'André Kaspi, intitulée Jules Isaac, historien, acteur du rapprochement judéo-chrétien. L'ouvrage se concentrait plus volontiers sur l'historien que sur l'acteur du rapprochement judéo-chrétien. Isaac, jugé « inclassable » au terme de cette imposante étude, résistait en partie à l'analyse, tant le traumatisme de la Seconde Guerre mondiale semblait irrémédiablement diviser sa vie en deux identités séparées. D'une certaine manière, le travail ici entreprit par Norman C. Tobias prolonge l'étude de Kaspi, en ce qu'il s'intéresse plus à l'acteur du rapprochement judéo-chrétien qu'à l'historien, et propose pour cela de nouvelles considérations sur ce qui fit l'unité de la vie et de l'œuvre d'Isaac.

2 L'ouvrage, composé de treize chapitres, se divise à parts égales entre les années 1877-1945 et la période 1945-1963. Le chapitre consacré aux années de formation d'Isaac retrace la transformation de l'adolescent besogneux en un adulte à la conscience morale aiguisée. L'influence majeure de Charles Péguy, dont Jules Isaac rejoint le premier cercle, fut particulièrement structurante pour sa personnalité. Tout comme son aîné, Isaac était aspiré par une " libre et honnête recherche de la vérité ». Devenu enseignant, Isaac apprit à ses dépends qu'afficher sa passion républicaine dans un milieu bourgeois pouvait lui valoir quelques ennuis. Sollicité pour participer à ce qui deviendra les manuels Malet-Isaac, puis nommé Inspecteur général de l'Instruction publique, Isaac parvint toutefois à faire reconnaître ses qualités pédagogiques et intellectuelles. Passé du rang de " citoyen à lépreux » (chap. IV) au moment de la 
Seconde Guerre mondiale, Isaac se réfugia en zone non-occupée, jusqu'à ce que les activités de résistance de l'un de ses deux fils le fassent repérer. Son épouse, déportée, ne revint pas. Dès lors, Isaac entra dans la seconde phase de sa vie : il se donna pour « mission sacrée » de démontrer comment la lecture chrétienne des Évangiles a donné naissance à une haine anti-juive.

Rédaction de Jésus et Israël, opposition à Daniel-Rops, querelle avec Henri-Irénée Marrou, participation à la conférence de Seelisberg, mise en place des premiers groupements d'Amitié judéo-chrétienne, difficile positionnement par rapport à l'International Council of Christians and Jews et finalement audience auprès des papes Pie XII puis Jean XXIII : tous ces éléments sont connus des historiens. NCT leur donne cependant une lecture particulière, montrant comment " l'Inspecteur général honoraire [émerge] à la façon d'une figure nouvelle dans la sphère publique française, affranchi de sa chrysalide républicaine, laïque et socialiste, mais toujours animé d'un feu à la Péguy » (p. 178). L'auteur avance que le dialogue intérieur avec Péguy a soutenu ses nouveaux engagements. Isaac s'est affirmé, selon ses mots, « à mi-chemin, écartelé mais tendant les mains aux uns et aux autres, pour qu'ils se reconnaissent comme frères, en attendant de se rejoindre devant Dieu ». NCT, particulièrement attentif à la manière dont Isaac entra en relation avec les acteurs religieux (juifs, protestants, catholiques) de son temps et construisit son réseau d'amitiés, place Isaac au cœur d'une histoire des idées qui renouvelle notre connaissance d'une période que l'on pensait bien connue. L'ouvrage se termine au-delà du décès d'Isaac et s'intéresse tout particulièrement aux évolutions de Gregory Baum (membre de la sous-commission conciliaire chargée de la déclaration sur les Juifs) face aux thèses de Jésus et Israël, ce qui pousse NCT à risquer l'hypothèse (peut-être un peu trop enthousiaste) d'une influence indirecte d'Isaac (et, derrière lui, de Charles Péguy) sur le quatrième paragraphe de Nostra Aetate.

4 Le volume, au final, restitue Isaac dans son humanité et dans ses peines. L'empathie de NCT pour son sujet, conjuguée à son approche sensible à l'histoire des idées, inscrit pleinement le travail de Jules Isaac dans la filiation de Charles Péguy, dont on saisit combien la présence a pesé sur l'histoire de l'Église catholique par le biais de ses compagnons et de ses héritiers.

5 «Peu nombreuses sont les personnes conscientes du rôle de catalyseur joué par Jules Isaac dans la révolution de l'enseignement et de la prédication catholiques au sujet des juifs et du judaïsme » (p. 319). C'est par ces quelques mots que s'annonce la conclusion de l'ouvrage. Et l'on doit à l'auteur d'avoir brillamment mis en évidence ce rôle dans cet épais volume, dont il faut également souligner la qualité de la traduction depuis l'original anglais publié en 2017. 